Int. J. Dev. Biol. 62: 85-95 (2018)

https://doi.org/10.1387/ijdb.170315CT

\title{
The chick limb: embryology, genetics and teratology
}

\author{
MEGAN G. DAVEY ${ }^{1}$, MATTHEW TOWERS ${ }^{2}$, NEIL VARGESSON ${ }^{3}$ and CHERYLL TICKLE*,4 \\ ${ }^{1}$ Division of Developmental Biology, The Roslin Institute, University of Edinburgh, Edinburgh, UK, \\ ${ }^{2}$ Department of Biomedical Science and the Bateson Centre, University of Sheffield, Sheffield, UK, \\ ${ }^{3}$ School of Medicine, Medical Sciences \& Nutrition, Institute of Medical Sciences, University of Aberdeen, Aberdeen, \\ UK and ${ }^{4}$ Department of Biology and Biochemistry, University of Bath, Bath, UK
}

\begin{abstract}
The chick embryo has a long history in investigations of vertebrate limb development because of the ease with which its limbs can be experimentally manipulated. Early studies elucidated the fundamental embryology of the limb and identified the key signalling regions that govern its development. The chick limb became a leading model for exploring the concept of positional information and understanding how patterns of differentiated cells and tissues develop in vertebrate embryos. When developmentally important molecules began to be identified, experiments in chick limbs were crucial for bridging embryology and molecular biology. The embryological mechanisms and molecular basis of limb development are largely conserved in mammals, including humans, and uncovering these molecular networks provides links to clinical genetics. We emphasise the important contributions of naturally occurring chick mutants to elucidating limb embryology and identifying novel developmentally important genes. In addition, we consider how the chick limb has been used to study mechanisms involved in teratogenesis with a focus on thalidomide. These studies on chick embryos have given insights into how limb defects can be caused by both genetic changes and chemical insults and therefore are of great medical significance.
\end{abstract}

KEY WORDS: pattern formation, signalling, talpid, disease model, thalidomide

\section{Introduction}

The chick embryo has a proud history as a premier model for studying vertebrate limb development. The developmental stages and morphology of chick limbs conform to the typical vertebrate plan except that there are only three digits in the wing and four in the leg (Fig. 1). The chick limb came to prominence in the mid-20 ${ }^{\text {th }}$ century largely because of pioneering embryological experiments by John Saunders which identified key signalling centres involved in its development (Saunders, 1948; Saunders and Gasseling, 1968; reviewed Tickle, 2017). Lewis Wolpert and colleagues then used the chick limb to explore the role of signalling centres in specifying positional information in pattern formation- the developmental process that generates spatially organized arrays of differentiated cells and tissues (Wolpert, 1969). For details about why Wolpert decided to work on the limb see his contribution to this issue (Wolpert, 2018). The adoption of the chick limb as a model for pattern formation meant that it came to have a much wider significance, elucidating general principles that apply to other regions of the embryo. Experiments on the chick limb also showed that it is capable of self-organization and can generate a periodic pattern which is a feature of many biological systems.

The ease with which developing limbs can be manipulated in chick embryos provided the basis for uncovering the fundamental embryology. Classical manipulations include ablating parts of the limb, transplanting tissues to different positions, separating tissues and then recombining them, making tissue chimeras and fate maps. When developmentally important genes began to be discovered, experiments on chick embryos were crucial for bridging experimental embryology with molecular biology. Methods were devised to manipulate signalling pathways by grafting cells producing signalling molecules and implanting beads soaked in various chemicals. The use of beads, first pioneered in chick wing development (Eichele et al., 1984), has been adopted widely by developmental biologists to apply not only signalling molecules locally to embryos and organ cultures but also other chemicals such as small molecule inhibitors. Transient transgenesis in which gene expression constructs are delivered to developing chick limbs using retroviruses (Morgan et al., 1992) or by electroporation was

Abbreviations used in this paper: FGF, fibroblast growth factor; GFP, green fluorescent protein; Shh, sonic hedgehog; ZRS, zone of polarizing activity regulatory sequence.

\footnotetext{
*Address correspondence to: CheryllTickle. Department of Biology and Biochemistry, University of Bath, Bath, UK. E-mail: cat24@ bath.ac.uk (iD) http://orcid.org/0000-0001-7178-1092
} 
also introduced complementing emerging genetic approaches in the mouse. In the last 10 years or so, the creation of genomic resources and sequencing of the chicken genome have ensured that the chick remains at the forefront of limb research. In addition, transgenic chickens such as those expressing Green Fluorescent Protein (GFP) became available which have further enhanced chimeric limb analysis.

Naturally occurring chicken mutants have provided another route to understanding limb embryology and led to the discovery of novel developmental genes. Because generation of mouse limb mutants is now relatively routine, it is easy to overlook how valuable naturally occurring limb mutants are. Many classical recessive embryonic lethal chicken mutants, identified because of their failure to hatch, such as the talpid mutants, have abnormal limbs. Early researchers used these chicken mutants to illuminate limb embryology. And of course, nature frequently designs better experiments than scientists, creating novel phenotypes which can lead to unexpected avenues of understanding and identifying genes which might otherwise have been missed in mammalian systems.

Studies on the chicken embryo have been especially impactful because even though the morphology of the limbs of birds and mammals has diverged during evolution, the developmental mechanisms are generally conserved, including in humans. Furthermore, understanding chick limb development at the genetic level has provided direct links with clinical genetics and the genes responsible for limb abnormalities in patients (reviewed Zuniga et al., 2012). We will emphasise the clinical relevance of embryological and molecular studies on limb development in both normal and mutant chick embryos. In addition, although developmental biologists have generally focussed on genetic changes that cause limb abnormalities, exposure to harmful chemicals during embryonic development is another important cause. The chick embryo offers a fantastic model system to study how chemical teratogens produce limb defects live and in-vivo as it can be readily treated by injections into the yolk or by dropping solutions on to it. Romanoff (1972) lists over 100 inorganic and organic chemicals that have been applied to chick embryos and about a third of these were reported to affect limb development. Here we will concentrate on thalidomide, an infamous limb teratogen with a long history of being investigated in the chick embryo.

\section{Contributions of the chick to understanding limb embryology}

\section{Limb initiation and cell lineages}

Chick limbs develop from small buds that arise at appropriate levels along the main body axis (wing buds opposite somites 15-20, leg buds opposite somites 26-31). Transplantation experiments in chick embryos were instrumental in showing that limb -forming regions and their antero-posterior polarity are determined long before any limb buds are visible. Further cut and paste experiments indicated that signals from neighbouring tissues are involved in specifying the position of the limb-forming regions at the sides of the body (reviewed Tickle, 2015).

Experiments on chick embryos revealed the origins of the cells that make up the limb buds. The early limb bud consists of a vascularised core of undifferentiated mesenchyme cells encased in ectoderm with a thickened ectoderm around the rim of the bud known as the apical ectodermal ridge (apical ridge; Saunders, 1948). Chick-quail chimeras demonstrated that cells from adjacent somites migrate into the limb-forming regions and give rise to the myogenic cells of the muscles (Christ et al., 1977) and to the vasculature (Ambler et al., 2001). Likewise, chick-mouse chimeras demonstrated that mouse somitic cells can give rise to

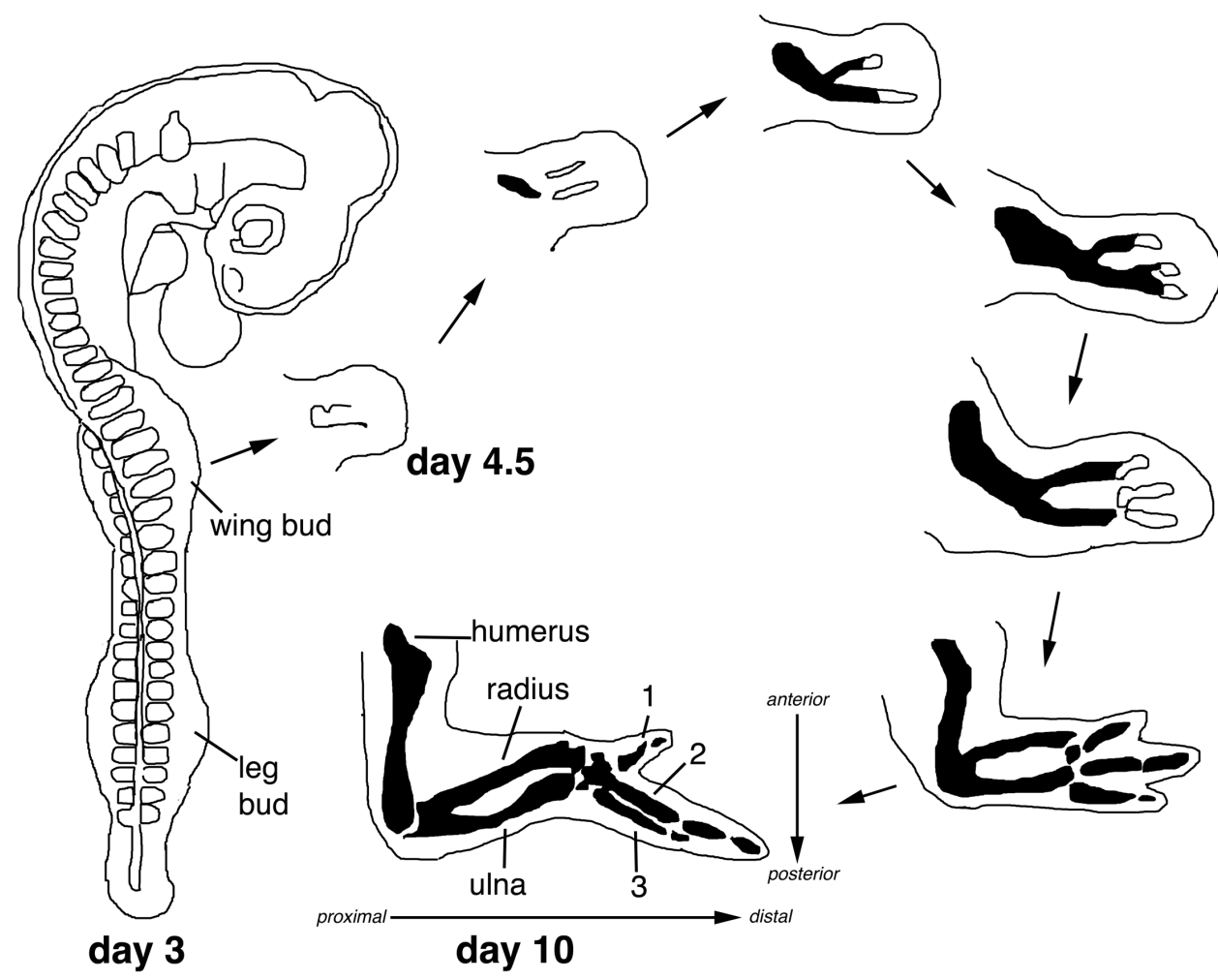

Fig. 1. Vertebrate limb development illustrated by the chick wing. Small protrusion from the flank forms bud, bud grows distally eventually acquiring characteristic wing shape. Skeletal development represented by condensations of chondrogenic cells (outlined within bud), cartilage differentiation (black). Skeletal elements laid down in sequence along proximo-distal axis starting with humerus, accompanied by splitting of dorsal and ventral muscle masses to form extensors and flexors respectively (not itlustrated). Series of condensations, giving rise to digits, form within hand-plate, digits then separated by programmed cell death in interdigital regions. Each digitmorphologically distinct in a precise pattern across anteroposterior axis, digit 1 anterior; digit 3 posterior (digits previously designated 234). Nerves grow into limb after pattern of skeleton and musculature established. Dorsal uppermost. Days = days after laying. Re-drawn afterTickle and Eichele (1994). 
limb myoblasts and angioblasts. The lateral plate mesoderm gives rise to the connective tissues (Pearse et al., 2007). Observations on chick embryos have shown that the lateral plate mesoderm in the limb-forming regions is augmented by cells from the coelomic epithelium that have undergone an epithelial-mesenchymal transition (Gros et al., 2014). The origin of the limb bud ectoderm has been traced in chick embryos using either chick-quail chimeras or the lipophilic dye, Dil, to label small groups of cells (Michaud et al., 1997; Altabef etal., 1997). The latter technique showed that the limb bud ectoderm consists of cell-lineage restricted dorsal and ventral compartments; ectoderm cells that will form the apical ridge are initially scattered and then migrate to the compartment boundary.

\section{The apical ectodermal ridge and limb bud outgrowth}

The apical ridge is required for outgrowth and laying down of the pattern of structures along the proximo-distal axis. Experiments by Saunders in the 1940's showed that when the apical ridge is surgically removed from chick wing buds, outgrowth ceases and truncated wings develop (Saunders, 1948; see also Summerbell, 1974). The level of truncation depends on the stage at which the apical ridge is removed, more severe truncations being produced when the ridge is removed at earlier stages. In contrast, an apical ridge grafted to the dorsal surface of a wing bud signals to the underlying mesenchyme inducing a new outgrowth (Saunders and Gasseling, 1968). Several chicken mutants have wings truncated at the shoulder girdle; a limbless mutant and four independent wingless mutant strains (Zwilling, 1974; Carrington and Fallon, 1984; Ohuchi etal., 1997a; Hinchliffe and Ede, 1973). Mesenchymal-ectodermal recombination experiments with wingless mutants have shown that the defect lies in the ectoderm (e.g. Hinchcliffe and Ede, 1977) confirming its crucial role in limb bud outgrowth first proposed by Saunders. Recombination experiments in which the apical ridge is exchanged between chick wing bud and chick leg bud and between chick wing bud and mouse fore-limb bud showed that its function is highly conserved between limb buds and between birds and mammals. Thus, congenital limb truncations in human patients could be caused by failure of apical ridge signalling.

\section{Proximo-distal patterning and relevance to limb deficiencies}

The current view of how the proximo-distal pattern of the vertebrate limb is specified comes almost exclusively from chick experiments. There has been a long-running debate about whether proximo-distal positional information is specified by the length of time that cells spend in a progress zone, a region of undifferentiated proliferating cells at the tip of the bud (Summerbell et al., 1973) or are pre-specified in the early bud (Dudley et al., 2002). In the former model, the apical ridge acts permissively to maintain the progress zone, consistent with normal wings developing after exchanging the apical ridge between wing buds at different developmental stages (reviewed Saunders, 1977). Recent experiments in which the long term fate of transplanted mesenchyme cells was followed using tissue from the GFP transgenic chicken demonstrated an intrinsic timing mechanism (Saiz-Lopez et al., 2015; Saiz-Lopez et al., 2017), while grafting experiments by others suggested that proximal positional information is specified in the early wing bud by diffusible signals from the body wall (Cooper et al., 2011; Rosello-Diez et al., 2011).

The mechanisms that specify proximo-distal pattern have implications for understanding the basis not only of distal deficiencies such as truncations but also phocomelia, a transverse deficiency in which proximal structures are absent or severely shortened, but distal structures relatively unaffected. The very early chick wing bud can recover after removing most of the mesenchyme provided the apical ridge is intact (Mahony and Vargesson, 2013). At slightly later stages, mesenchyme removal (Mahony and Vargesson, 2013) and X-irradiation and treatments with chemicals such as nitrogen mustard, which kill mesenchyme cells, lead to phocomelia. According to the progress zone model, the sparing of distal structures would be due to cells spending longer in the progress zone in order to replace missing cells, thus becoming distalized (Wolpert et al., 1979). An alternative interpretation is that proximal cell populations are selectively eliminated (Galloway et al., 2009). Both truncated limbs and phocomelia are seen in patients whose mothers took thalidomide at a critical period during pregnancy and experiments on chick embryos have contributed to understanding how thalidomide causes these defects.

\section{Studies in the chick on limb deficiencies produced by thalidomide}

The chick embryo was one of the first models used to investigate the mechanisms of thalidomide action. Perhaps surprisingly, thalidomide has little effect on rodent embryos, so research on its actions has necessarily been carried out on other organisms (Vargesson, 2013). Initial studies indicated that thalidomide is harmful to early chick embryos and injection into the yolk caused facial and spinal anomalies and shortening and stunting of the legs (Boylen et al., 1963). In another study, thalidomide was applied directly over the wing bud and this damaged and dilated the axial artery supplying it (Jurand, 1966). It was not until seminal work by Judah Folkman and colleagues (D'Amato et al., 1994), using rodent angiogenic cornea assays, however that it was proved that thalidomide is anti-angiogenic. This discovery suggested that the teratogenic effects of thalidomide on limb development are due to these inhibitory effects on angiogenesis. Radiography of thalidomide survivors indicating altered nerve patterns and some rabbit embryo work showing loss of nerves in thalidomide damaged limbs had led to an alternative theory that thalidomide targets neural crest and nerves (McCredie and McBride, 1973). Studies on chick embryos showed that experimentally inhibiting innervation of developing limbs did not produce defects although they were shorter (Strecker and Stephens, 1983; Mahony et al., In press) so nerves are more likely to be affected secondarily.

Structural analogs of thalidomide which have either anti-inflammatory actions or anti-angiogenic actions have been screened in chick embryos. Anti-inflammatory thalidomide analogs and other metabolic by- products of the drug did not cause any developmental defects. But the antiangiogenic analog, CPS49, caused a range of wing defects including truncations and phocomelia, the precise defect depending on the stage at which the embryos were treated (Therapontos et al., 2009; Fig. 2). A crucial observation was that blood vessel damage was detected within a couple of hours of treatment resulting in large areas of the wing bud becoming avascular and this was followed by cell death several hours later. Interestingly, only newly formed or forming vessels were destroyed, whereas those no longer undergoing angiogenesis which possessed smooth muscle coats were unharmed. This could explain why thalidomide appears to have specific effects on the limbs as these are the main organs at these stages in which angiogenesis 
is occurring (Vargesson and Laufer, 2001). The key importance of thalidomide-effects on blood vessels was further emphasised by finding that molecules which protect blood vessels, such as nitric oxide, prevent thalidomide-induced limb defects in chick embryos (Siamwala et al., 2012).

These observations on chick embryos indicate that the antiangiogenic action of thalidomide could cause its teratogenic effects on human limb development. But questions remain about how damaged blood vessels lead to the specific limb defects such as phocomelia (Tabin, 1998). As hypothesised for the effects of Xirradiation on the chick wing (Wolpert et al., 1979), loss of newly formed or forming vessels in the developing limb could result in mesenchymal cell death in the progress zone resulting in distalization of remaining cells. Anti-angiogenic, anti-cancer drugs, Sunitinib and Sorafenib, both antagonists of the signalling pathway involved in angiogenesis, also result in limb abnormalities when applied to chick embryos (Beedie et al., 2016a). This suggests that all antiangiogenic drugs need to be carefully regulated to ensure they are not taken by pregnant women.

The polarizing region and antero-posterior pattern formation

Experiments carried out on chick wing buds by Saunders led to the discovery of the zone of polarizing activity (ZPA; polarizing region), the small region of mesenchyme cells at the posterior margin of the early limb bud which specifies antero-posterior pattern (Saunders and Gasseling, 1968). When the polarizing region from a chick wing bud was grafted to the anterior margin of another wing bud, up to six digits developed instead of three, with additional digits arising from the anterior part of the bud in mirrorimage symmetry with the normal set; the pattern of the fore-arm including the muscle pattern can also be duplicated (Shellswell and Wolpert, 1977).

A long-standing model for polarizing signalling in the chick wing bud is based on the concept of positional information (Wolpert, 1969). It was proposed that the polarizing region secretes a morphogen that spreads across the bud and establishes a concentration gradient with cells being informed of their position by the local morphogen concentration; cells then interpret this information to form the appropriate structure. Positional information is established in the early wing bud and then remembered. A wealth of experiments supports this model but also revealed that timing and direct effects on growth are involved (reviewed Towers and Tickle, 2009). It had also been known for a long time that chick limb mesenchyme is able to self-organize. When the mesenchymal core of chick limb buds is disaggregated into single cells, then reaggregated and placed back inside an ectodermal jacket, such "recombinant limb buds" give rise to a series of repeated digit-like structures (reviewed Saunders, 1977). However, when a polarizing region is grafted to one edge of a "recombinant limb", the antero-posterior digit pattern is re-established. Thus, self-organization, postulated to occur via a Turing-type mechanism, might co-operate with positional information (Wolpert, 1989; Green and Sharpe, 2015; Pickering and Towers 2016). Other experiments on developing chick legs showed that digit morphology can be altered at the foot-plate stage by grafting mesenchyme from one interdigital space to another (Dahn and Fallon, 2000) indicating that further signalling interactions translate positional information into final digit anatomy.

Polarizing activity has been detected when tissue from the posterior margin of mammalian limb buds, including human limb buds, is grafted to the anterior margin of chick wing buds resulting in induction of additional digits (Fallon and Crosby, 1977). These experiments show that polarizing region signalling is highly

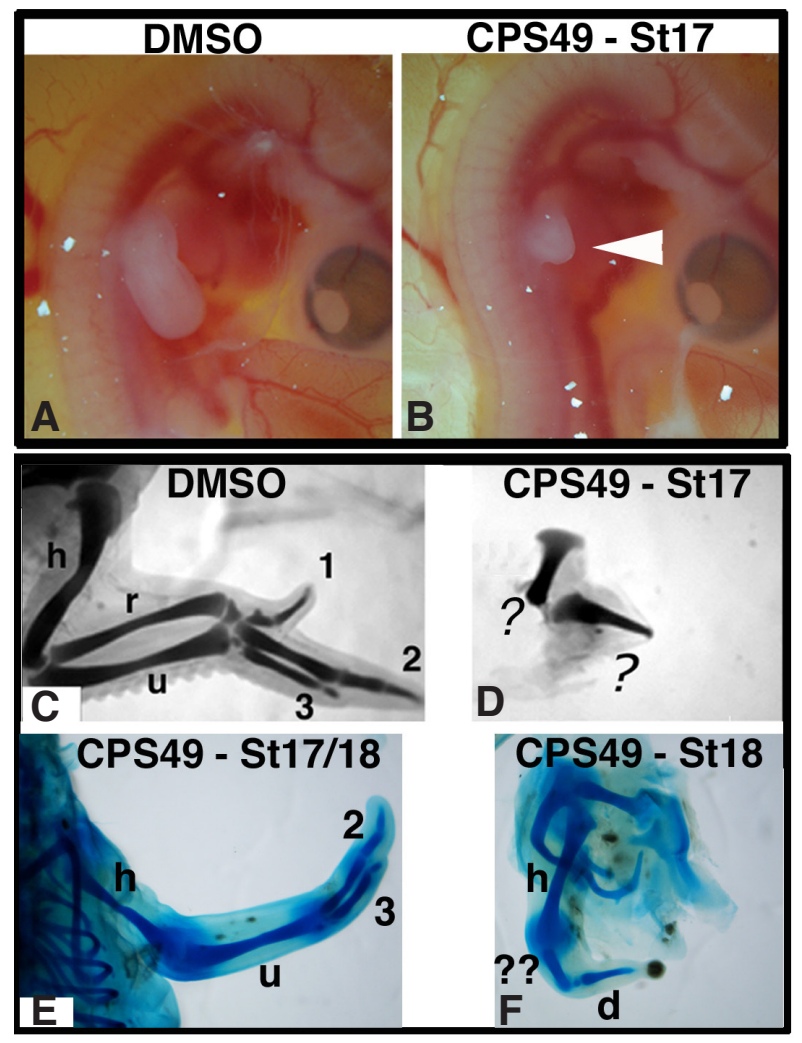

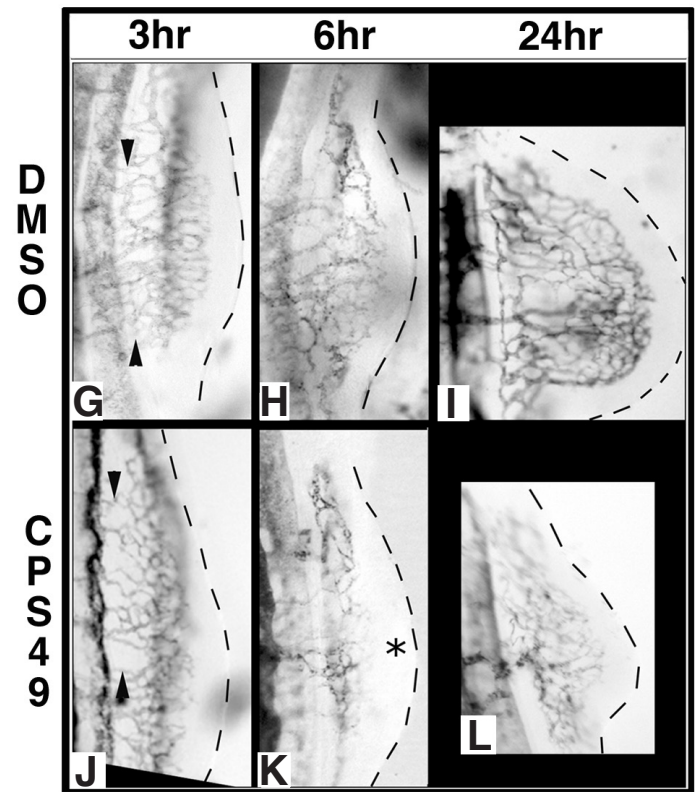
wing bud severely stunted with markedly reduced vasculature (L compare with I, bud with highly patterned and intricate vascular network). Abbreviations: St, Hamburger-Hamilton stage treatment; $h$, humerus; $u$, ulna; r, radius; 1, digit1; 2, digit2; 3, digit3; $d$, unidentified digit; ?, two severely truncated articulating cartilage elements; ??, shortened ulna. (A-D, G-L) Modified from Therapontos et al., (2009). (E,F) Images from N. Vargesson (University of Aberdeen, Scotland). 


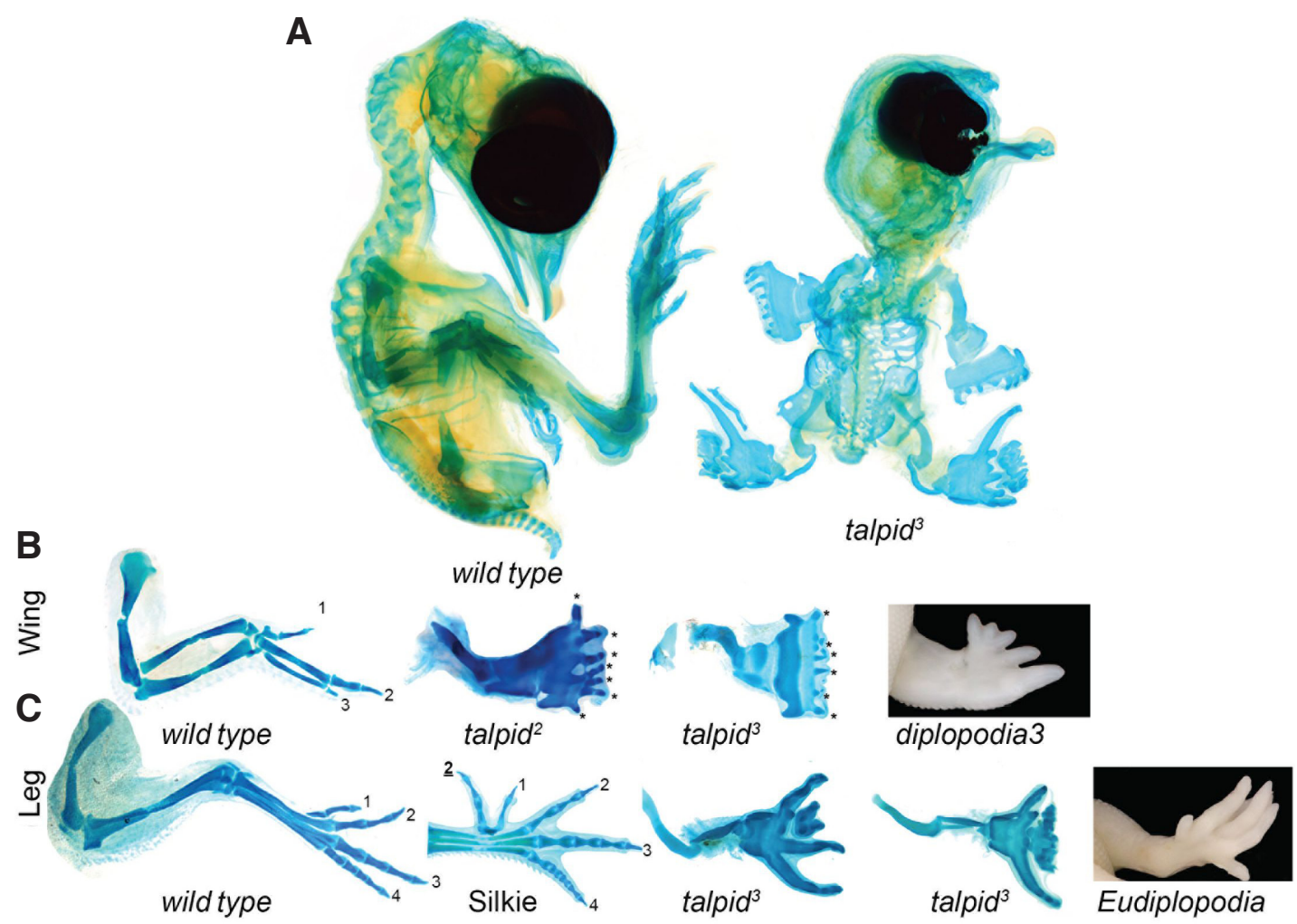

Fig. 3. Chicken mutants. (A) Cartilage skeletons of E14 talpid ${ }^{3}$ mutant and normal sibling, showing polysyndactylous wings and legs in mutant. Note other malformations - 'peg' like lower jaw, holoprosencephaly, loss of upper jaw. (B) Comparison of normal wing, talpid ${ }^{2}$ wing (Samantha A. Brugmann, Cincinnati Children's Hospital), talpid ${ }^{3}$ wing and diplopodia ${ }^{3}$ wing (E.A. O'Hare and M.E. Delany, UC Davis); all polysyndactylous but with variations. $\mathrm{dp}^{3}$ maintains digit identity (not shown) whereas talpid ${ }^{2}$ and talpid ${ }^{3}$ do not. (C) Comparison of normal leg with digits 1, 2, 3, 4 (from anterior to posterior), Silkie leg with preaxial polydactyly (digits 2, 1 , 2, 3, 4), two talpid ${ }^{3}$ legs showing variable polysyndactyly and Eudiplopodia leg (E.A. O'Hare and M.E. Delany, UC Davis) with polydactyly and additional digits arising dorsally and ventrally. conserved and that digit anatomy depends on the interpretation of positional information as the additional digits induced are chick wing digits. In the chick leg, the most posterior digit comes from the polarizing region itself and in the mouse limb, the two most posterior digits (reviewed Tickle and Towers, 2017). It has been suggested that these posterior digits are specified by a timing mechanism whereas the anterior digits are specified, as in the chick wing, by graded signalling. The implication of these studies is that pre-axial polydactyly in human patients -additional digits anteriorly -could be caused by having polarizing activity at both anterior and posterior margins of the limb bud.

\section{The polarizing region and maintenance of the apical ectodermal ridge}

The polarizing region has a pivotal role not only for specifying the antero-posterior pattern of structures that develop distal to the elbow/knee but also maintaining the apical ridge over the adjacent posterior part of the bud. The antero-posterior extent of the apical ridge determines the width of bud outgrowth and, consistent with a Turing-type mechanism, the number of digits is determined by bud width. That the distal structures arise from the posterior part of the wing bud has been shown by generations of fate maps through marking mesoderm cells with carbon particles, chick-quail chimeras, Dil labelling, and confirmed by grafts from the GFP chicken (reviewed Towers and Tickle, 2009; Towers et al., 2011). It was proposed that the polarizing region controls production of a factor - apical ectoderm maintenance factor - which maintains the apical ridge (reviewed Saunders, 1977). This dependence of the apical ridge on the polarizing region signalling means that limb truncations could arise indirectly because of defective polarizing region signalling. It was also shown that polarizing region grafts have to be grafted adjacent to the ridge in order to induce additional digits suggesting that the polarizing region is maintained by the apical ridge.

\section{Polarizing activity in talpid polydactylous chicken mutants}

Talpid² (Abbott et al., 1960) and talpid ${ }^{3}$ (Ede and Kelly, 1964) both have polysyndactyly- limbs with many fused digits (Fig. 3). The formation of many digits in talpid ${ }^{3}$ correlates with broadened limb buds and an antero-posteriorly extended apical ridge. Donald Ede's work on talpid ${ }^{3}$ was ahead of its time and culminated in the first mathematical computer model of limb bud growth. The model could simulate the broadened talpid ${ }^{3}$ limb bud based on unrestricted growth across the antero-posterior axis (Wilby and Ede, 1975). Mesenchymal-ectodermal recombination experiments with talpid ${ }^{3}$ wing buds revealed that the defect lies in the mesenchyme and that dissociated talpid ${ }^{3}$ limb mesenchyme cells could form digits spontaneously. Moreover, grafting the polarizing region from talpid wing buds to normal wing buds showed that the talpid ${ }^{3}$ mutation caused a failure of the talpid ${ }^{3}$ cells to receive, but not transmit the polarizing signal (Ede and Shamslahidjani, 1983).

\section{Ectoderm and dorso-ventral pattern formation}

Chick experiments showed that the ectoderm covering the sides of the bud controls the dorso-ventral pattern (reviewed Saunders, 1977). In mesenchymal-ectodermal recombinations, in which the dorso-ventral axis was reversed relative to the mesenchyme, the polarity of distal structures conformed to the polarity of the ectoderm. The importance of ectodermal signals in controlling dorso-ventral pattern was further demonstrated by the "double-dorsal" muscle pattern of supernumerary wing bud tips - induced by grafting an apical ridge to the dorsal surface of a wing bud - which were covered 
on both sides by dorsal ectoderm (Shellswell and Wolpert, 1977). A "double-dorsal" pattern indicated by conical nails was also observed in two toes arising from the dorsal surface of a polydactylous human limb (D'Souza et al., 1998) suggesting that the ectoderm controls dorso-ventral pattern in human limb development.

\section{Insights into the molecular basis of limb development from the chick}

\section{Apical ectodermal ridge signalling}

Studies on the mouse limb showed that the apical ectodermal ridge expresses Fgf4 and Fgf8 and a key experiment in the chick wing showed that a bead soaked in an FGF protein could substitute for an extirpated apical ectodermal ridge (Niswander et al., 1993). In the Japanese wingless mutant, Fgf4 is expressed in the apical ectodermal ridge at first but later lost. Just as an FGF4 bead rescues normal wing development after apical ridge removal, the Japanese wingless wing can similarly be rescued by implanting an FGF bead, thus showing that the wingless defect lies in failure to maintain Fgf4 signalling in the apical ridge (Ohuchi et al., 1997a). The fact that only wings are absent in the mutant points to an unexpected difference in apical ridge maintenance in wing versus leg.

Even more strikingly, FGFs, applied on beads to the interlimb flank of a chick embryo, induce ectopic limbs (Cohn et al., 1995). This finding contributed to uncovering the role in limb initiation for mesenchymal FGFs (Fgf10), which operate in positive feedback loops with FGF and Wnt family signalling ligands produced by the apical ridge (Ohuchi et al., 1997b). Subsequently, it emerged that Wnts are also expressed in the apical ridge and grafts of Wnt-producing cells to the interlimb flank of a chicken embryo also induce ectopic limbs (Kawakami et al., 2001). Fgf10, in cooperation with the transcription factor Tbx5, is involved in the early delamination of cells of the coelomic epithelium, which contribute to the limb bud mesenchyme. Tbx5 and its close relative Tbx4 have striking expression patterns -first shown in chick embryos -with $T b x 5$ being expressed specifically in wing buds and Tbx4 in leg buds. Subsequent work in transgenic mice showed that Tbx5 is essential for fore-limb development and that $T b x 4$ can replace the its function suggesting that the genes have equivalent functions in developing limbs (reviewed Nishimoto and Logan, 2016). Tbx5 mutations are found in patients with Holt-Oram syndrome, characterized by arm and heart defects.

FGFs are expressed in the apical ridge throughout the laying down of the entire proximo-distal pattern. Experiments in the chick leg have shown that regression of the apical ridge and consequent cessation of FGF signalling induces formation of the terminal phalanx of a digit while extending FGF signalling experimentally leads to development of an additional phalanx (Sanz-Ezquerro and Tickle, 2003). Mutations in FGF receptors are clinically important, for example, in patients with Aperts syndrome who have digit anomalies.

As already mentioned, the prevailing model for how proximodistal positional values are specified involves an intrinsic timing mechanism that operates in cells in a progress zone. However, the specification of proximal structures appears to involve retinoic acid signals from the flank counteracting FGF signals from the apical ridge (Cooper et al., 2011; Rosello- Diaz et al., 2011). As the wing bud elongates away from the flank, the concentration of retinoic acid falls and this starts the timing mechanism (Saiz-Lopez et al., 2015). This role in proximal limb patterning could be coupled with a role in limb initiation, since retinoic acid receptor antagonists inhibit chick wing development. Recent work also suggests that retinoic acid could be involved in chick leg initiation (reviewed Nishimoto and Logan, 2016). However, these roles for retinoic acid are still debated.

\section{Molecular basis of proximo-distal positional values}

It remains unclear how positional information is encoded along the proximo-distal axis. Good candidates include the products encoded by 5 'genes of the Hoxa and Hoxd clusters with spatially restricted overlapping expression patterns. Detailed analysis in chick limbs led to the suggestion that there are two phases of expression (Nelson et al., 1996) and subsequent work in the mouse has identified two different enhancers on either side of the Hoxd cluster (Montavon and Duboule, 2013). Extensive genetic analyses in the mouse limb including the creation of multiple knock-outs suggested that different combinations of Hox genes control regional identity along the proximo-distal axis (Wellik and Capecchi, 2003). Hoxd13 and Hoxa 13 specify the digits and mutations in these genes have been detected in patients with synpolydactyly and hand-foot-genital syndrome respectively.

Other transcription factors may also influence regional identity. The genes encoding Meis 1 and Meis 2 transcription factors are expressed in cells that give rise to proximal structures and studies in the chick showed that they are responsive to retinoic acid signalling (Mercader et al., 2000). The Shox transcription factor could also contribute to specifying positional identity. Shox is expressed in cells in the chick wing bud that give rise to the ulna/ radius and is repressed by to both retinoic acid and FGF signals (Tiecke et al., 2006). Mutations in SHOX have been identified in patients with short stature conditions such as Langer mesomelic syndrome in which the lower arm and lower leg are particularly short and SHOX deficiency contributes to Turner syndrome. The mouse does not have a Shox gene -only the closely related gene Shox2 - so the chick provides the experimental model for studying its function. Furthermore an in vivo assay in the chick wing bud identified enhancer activity in regions downstream of SHOXdeleted in short stature patients who have an intact coding region for the gene thus providing an explanation for their condition (Sabherwal et al., 2007).

\section{Polarizing region signalling}

The first molecule found to mimic signalling of the polarizing region was retinoic acid and application of retinoic acid to the anterior margin of a chick wing bud resulted in mirror image duplications of the pattern of digits (Tickle et al., 1982). The demonstration that retinoic acid acted in a concentration and time-dependent manner, required of a polarizing region signal, was consistent with it being the endogenous signal. However, further experiments on the chick wing indicated that retinoic acid induced a new polarizing region and that the secreted signalling molecule Sonic hedgehog (Shh; Riddle et al., 1993) is the polarizing region morphogen.

Shh expression coincides with maps of polarizing region activity at the posterior margin of the chick wing bud and Shh protein can duplicate the pattern of chick wing digits when provided by transfected cells or on beads grafted to the anterior margin of the bud. The crucial role for Shh was further revealed by the loss of digits, in chick limbs, when cyclopamine was applied to inhibit Smoothened (Smo), the transmembrane protein that activates the 
Shh intracellular transduction pathway, and in mouse limbs, when Shh was functionally inactivated (reviewed Tickle and Towers, 2017). Furthermore, in mouse mutants with preaxial polydactyly, such as Sasquatch, Shhis expressed both anteriorly and posteriorly in the limb buds. Sasquatch is an insertional mouse mutant and particularly informative as ectopic Shh expression in the limb bud is caused by the transgene inserting into a long range regulatory sequence that controls Shh expression specifically in the limb, now known as the Zone of Polarizing activity Regulatory Sequence (ZRS; reviewed Hill and Lettice, 2013). Chromosomal breakpoints or mutations in the ZRS are associated with pre-axial polydactylous conditions in human patients as well as in cats and dogs. Deletion of the entire ZRS region in mice leads to loss of digits and mutations in this region occur in the human condition Acheiropodia in which structures distal to the elbow and knee are missing.

\section{Chicken breeds and mutants with ZRS-associated mutations}

Many Asian chicken breeds, such as the Silkie, with extra toes - pre-axial polydactyly (Fig. 3)- have a dominant point mutation in the ZRS resulting in ectopic Shh expression at the anterior of the leg bud (Dunn et al., 2011, Maas et al., 2012). The polydactylous locus in European polydactyous breeds derived from the Dorking breed also maps to an area containing the ZRS but is not the same mutation (Zhang et al., 2016). It has been generally concluded from these observations that the ZRS sequence inhibits Shh expression in the anterior of the limb bud but genetic crosses between polydactylous Silkie birds and non-polydactylous revertants with a normal ZRS sequence showed that the ZRS also controls the level of Shh signalling in the posterior (Johnson et al., 2014).

In contrast to these polydactylous breeds, the recessive oligozeugodacytly chicken mutant (ozd) lacks the ulna and all the digits in the wing and the fibula and digits 2-4 in the leg (Symth et al., 2000) reminiscent of the limb of Shh mouse mutants. John Fallon and collaborators showed that Shh expression is absent specifically in the limb buds but that adding recombinant Shh protein to the ozd wing buds restored the normal pattern, consistent with the ozd mutation affecting Shh expression itself, rather than disrupting downstream signalling (Ros et al., 2003). Mapping of the ozd mutation revealed a large 1654bp deletion partially overlapping the ZRS (Maas et al., 2012) thus explaining the lack of limb bud Shh expression.

\section{Insights into mechanisms of Shh signalling from the chick}

Extensive experimental analyses on the chick wing have defined the parameters by which graded Shh signalling specifies anteroposterior positional values and directly stimulates mesenchyme proliferation (Towers et al., 2008). In addition, a key finding from experiments on chick limb buds is that Fibroblast Growth Factor 4 (Fgf4) signalling by the apical ridge maintains Shh expression in the polarizing region, while, in turn, Shh signalling maintains Fgf4 expression in the apical ridge, thus establishing a positive feedback loop that maintains bud outgrowth (Niswander et al.,
1994, Laufer et al., 1994). Work on the mouse identified the BMP (Bone Morphogenetic Protein) antagonist, Gremlin1, as the apical ectoderm maintenance factor postulated by earlier grafting experiments on the chick wing.

A gradient of Shh has been demonstrated across the anteroposterior axis of chick wing buds (Zeng et al., 2001) but it is unclear whether this occurs by free diffusion and/or by active transport between cells in specialised structures called filopodia which have been studied in chick limb mesenchyme cells (Sanders et al., 2013). Mathematical modelling of digit specification in the chick leg is consistent with the polarizing region producing a digit in response to the timing of Shh signalling (Woolley et al., 2014). In the chick wing, the duration of Shh expression in the polarizing region is controlled by a timing mechanism, initially set by the level of retinoic signalling (Chinnaiya et al., 2014). Thus, as with proximo-distal patterning, antero-posterior patterning can involve both graded signalling and time-based mechanisms.

What is the basis by which graded Shh signalling specifies antero-posterior positional values? Genetic analyses in the mouse demonstrated that the transcriptional effectors of Shh signalling are the Gli transcription factors, (Gli1, 2 and 3). Gli3 plays the predominant role in the developing limb and functions primarily as a transcriptional repressor. Shh prevents the processing of the full-length Gli3 protein into a repressor form and a gradient of Gli3A/Gli3R from posterior to anterior has been demonstrated in the chick wing and the mouse limb (reviewed Tickle and Towers, 2017). Mutations in Gli3 are associated with human congenital limb abnormalities.

\section{Chicken talpid mutants and ciliopathy genes}

When Shh was identified as the molecule primarily responsible for signalling of the polarising region, it was initially surprising that Shh expression itself appeared to be localised normally to the posterior margin of the polydactylous talpid ${ }^{3}$ limb buds. However, Ptch1, which encodes the Shh receptor and is a direct target of Shh signalling, was not expressed at high levels (Lewis et al., 1999). Thus, the talpid ${ }^{3}$ defect lay, as Ede had inferred 30 years earlier, in reception, not the generation of the polarising region signal. But why would loss of Shh signal perception cause polydactyly rather than a loss of digits as in Shh mutant mouse embryos? The answer lay in a small organelle, the primary cilium, which projects from the surface of most cell types in the developing embryo and adult. After a decade of analysis, we now know that Ptch1 and Smo are localised to primary cilia during different phases of activation of the Shh pathway- Ptch1 during Shh signalling, Smo when there is no Shh signalling - and, furthermore, that the Gli transcription factors have to be trafficked through the cilia, where they are modified to allow them to enter the nucleus to repress or activate expression of Shh target genes (reviewed Bangs and Anderson, 2017).

Cilia are increasingly associated with a class of human congenital diseases- the 'ciliopathies' which are due to loss of cilia or impaired cilia function. They include organ specific ciliopathies such as

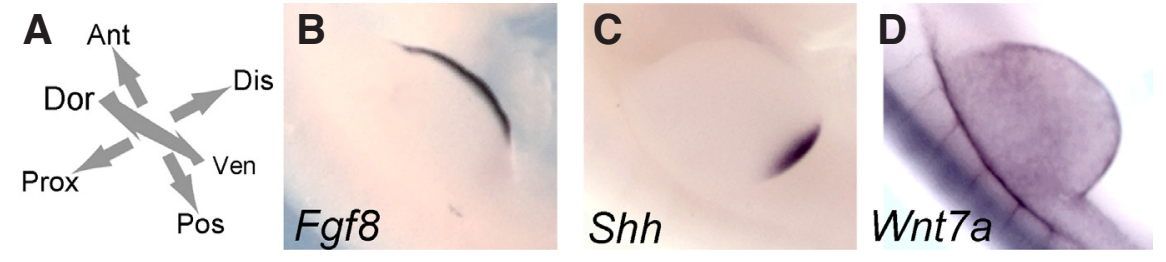

Fig. 4. Expression patterns of genes encoding important signalling molecules in early chick wing bud. (A) Three main axes. (B) Fgf8 in apical ectodermal ridge rimming distal tip. (C) Shh in polarizing region at posterior margin. (D) Wnt7a in dorsal ectoderm. Prox, proximal; Dis, distal; Dor, dorsal; Ant, anterior; Pos, posterior; Ven, ventral. 
polycystic kidney disease and retinopathies, and syndromes such as Biedel- Bardot syndrome, Orofacial -digital syndrome (OFD), and Short-rib polydactyly which frequently include polydactyly. In 2006, talpid $^{3}$ was mapped in to a novel gene- KIAA0586 (Davey et al., 2006). TALPID3/KIAA0586 was subsequently shown to be a centrosomal protein, the loss of which causes absence of all cilia (both primary and motile cilia) not only in chicken (Yin et al., 2009), but also mouse and zebrafish (reviewed Bangs and Anderson, 2017). Talpid ${ }^{2}$ was later shown to encode a known centrosomal protein C2CD3 (Chang et al., 2014). Both TALPID3/KIAA0586 and C2CD3 proteins localise to the basal body- a modified centriole which forms the base of a cilium. In the case of TALPID3/KIAA0586, loss of the protein causes failure of the centriole to migrate to the cell surface and dock with the plasma membrane (Stephen et al., 2014). As almost all cilia are lost, Shh signalling via the Gli transcription factors is neither fully activated nor repressed. The function of $\mathrm{C} 2 \mathrm{CD} 3$ is still elusive but the number of cilia is severely reduced, compromising Shh signalling.

The study of these chicken mutants has spearheaded novel advances because they have been informative about both mechanisms involved in ciliogenesis and human disease loci as patients with TALPID3 and C2CD3 gene mutations have been identified (reviewed Bangs and Anderson, 2017). TALPID3 mutations in human are usually recessive and cause a range of phenotypes from early embryonic lethality with polydactyly and craniofacial defects through to syndromes such as Jeune and Joubert syndromes which affect other parts of the body. Mutations in C2CD3 were already known to cause an OFD-type ciliopathy characterised by polysyndactyly and other abnormalities.

\section{Molecular basis of antero-posterior positional values}

One response to polarizing region signalling at the anterior margin of a chick wing bud is mirror-image duplication in gene expression patterns across the antero-posterior axis, including expression of 5'genes belonging to Hoxa and Hoxd clusters. The nested expression of Hoxd genes, centred on the posterior-distal region of the early limb bud in the first phase of expression suggested that they encode antero-posterior position. Furthermore, in talpid limb buds, Hoxd genes are instead expressed throughout the antero-posterior axis correlating with loss of digit identity. When Hoxd11 was overexpressed in chick limbs using retroviruses- the first time this retroviral technique was used in the limb - an additional digit developed (Morgan et al., 1992). It is likely however in the light of subsequent work in the mouse that this was due to inducing ectopic Shh expression.

Other molecules that could encode antero-posterior positional information acting downstream of Shh in the wing bud include the T-box transcription factors, Tbx2/3, expressed in distinct anterior and posterior stripes and the transcription factors, Sall1 and Sall3, also expressed in regions fated to become digits (Fisher et al., 2011). Overexpression of $T b x 2 / 3$ in the developing chick leg by retroviral vectors, resulted in additional phalanx formation and apparent posterior transformations in digit identity (Suzuki et al., 2004). These families of transcription factors are clinically relevant, for example, patients with a SALL4 mutation, have limb reductions. Many other conserved gene targets of Shh signalling have been identified following genomic screens in chick and mouse limbs (Bangs et al., 2010, Vokes et al., 2008), including BMPs, implicated as secondary signals acting downstream of Shh signalling and specifying antero-posterior positional values in the chick wing. Further targets of Shh signalling regulate proliferation and include $N$-myc and Cyclins D1 and D2 - explaining the direct effect of polarizing region grafts on wing bud growth.

BMPs are produced by the interdigital regions between the digit condensations and manipulations of BMP signalling at these stages alter digit morphology accounting for the effects of grafting interdigital mesenchyme (Suzuki et al., 2008). Interestingly, SMAD activity, a read-out of the response to BMP signalling, is graded between adjacent digit condensations, mirroring earlier graded Shh signalling, thus providing a connection between specification of positional information and later interpretation (eg: Vargesson and Laufer, 2009). To define the molecular basis of the identity of the digit condensations -and gain insights into homologies, the transcriptomes for each digit condensation in the chick wing and chick leg were analysed but revealed both similarities and differences (Wang et al., 2011).

\section{Molecules mediating dorso-ventral patterning}

Significant progress has been made in identifying molecules produced by the ectoderm that specify dorso-ventral pattern (reviewed Tickle and Towers, 2009). Wnt7a is expressed by the dorsal ectoderm of both chick and mouse limb buds and genetic deletion of Wnt7a in the mouse demonstrated its role in dorsal patterning producing "double --ventral" digits. Agood candidate for a factor encoding dorsal positional information is the transcription factor $L m \times 1 b$. $L m x b 1$ is expressed by the dorsal mesenchyme of the chick wing and acts downstream of Wnt7a. Retroviral overexpression of $L m \times 1 b$ in the chick wing resulted in ventral to dorsal transformations of the mesenchyme (Riddle et al., 1995; Vogel et al., 1995) similar to the "double -dorsal" wings induced by grafting an apical ridge to the dorsal side of a wing bud. Further analyses in the mouse revealed that loss of $L m x 1 b$ results in a "double -ventral" phenotype - in which nails fail to form on either side of the digits. $\angle M B X 1$ is the gene responsible for nail-patella syndrome which affects development of these dorsal structures.

Experiments in chick wing buds showed that BMP signals produced by the ventral ectoderm specify ventral pattern (Pizette et al., 2001). Genes acting downstream of BMP signalling in the ectoderm include Engrailed 1, and its inactivation in the mouse limb results in a "double-dorsal" phenotype. Experiments on the chick wing showed that over-expression of Engrailed-1 results in loss of Wnt7a expression in dorsal ectoderm (Logan et al., 1997). Therefore, Engrailed-1 determines ventral fate by repressing expression of the dorsalizing factor gene Wnt7a.

Limbs of Wnt7a-/- mice lack posterior digits, found to be due to reduced Shhexpression at the posterior limb bud margin. Additional work on the chick wing, removing the dorsal ectoderm surgically, also revealed that Wnt7a regulates Shh expression (Yang et al., 1995). The importance of this effect of Wnt signalling is that it integrates patterning along antero-posterior and dorso-ventral axes.

\section{Conclusions}

We have highlighted how studies of chick embryos elucidated the basic biology of limb development and helped uncover its genetic basis. We have not attempted to be comprehensive - transcriptome analysis estimates that about 10,000 genes are expressed in the chick wing bud! (Boardman et al., 2003)- but underscored 
genes for signalling molecules and transcription factors with crucial functions particularly those of clinical relevance. Future progress towards obtaining a more complete picture will include applying more genomic level approaches. We anticipate that the chick limb will feature in such endeavours and complement studies on mammalian limbs. Successes in delivering the gene editing CRISPR/ Cas9 system to chick embryos by electroporation have been reported (e.g. Veron et al., 2015) and this could provide an important new tool for future studies.

Throughout this review, we featured chicken mutants - in particular, their contributions to identifying new genes involved in limb development - also studies on teratogenesis using chick embryos. With respect to chicken mutants, there is considerable scope for further advances. The genes affected in the limbless / wingless mutant strains are currently unknown as are those in other avian mutants such as the quail mutant hereditary multiple malformations and the diplopodia chicken mutants $\left(d p^{1}, d p^{3}, d p^{4}\right.$; Fig. 3) which may or may not be ciliopathies and the chicken eudiplopodia mutant which has multiple apical ridges. Uncovering the genes affected, just as in the chicken talpid mutants, may give unexpected insights into human disease (Robb et al., 2011). With respect to teratogencity, the developing chick limb is currently being used to test drugs such as Valproate (Whitsel et al., 2002) as well screening thalidomide analogs to identify those clinically beneficial but not teratogenic (Beedie et al., 2016b). This screening is necessary because thalidomide is being widely used in parts of Brazil to treat complications of leprosy and tragically a new generation of thalidomide babies has been born (Vargesson, 2015). Finally, the studies on thalidomide spotlighted the limb vasculature. Intriguingly, the vasculature of talpid ${ }^{3}$ limb buds is abnormal with accompanying changes in expression of angiogenic signalling molecules (Davey et al., 2007). This suggests that focussing on the development of the limb vasculature would be a very valuable area for future research and an area in which chick embryos could make important contributions.

\section{Acknowledgements}

$M D$ is supported by the BBSRC through a BBSRC Institute Strategic Grant, MT is a Wellcome Trust Senior Fellow and NV's studies on thalidomide were supported by The Wellcome Trust. We all thank lab members past and present for their help and support. We apologize to those whose work we have not referenced due to lack of space.

\section{References}

ABBOTT UK, TAYLOR LW, ABPLANALP H (1960). Studies with talpid², an embryonic lethal of the fowl. $J$ Hered 51: 195-202.

ALTABEF M, CLARKE JDW, TICKLE C (1997). Dorso-ventral ectodermal compartments and origin of apical ectodermal ridge in developing chick limb. Development 124: 4547-4556.

AMBLER CA, NOWICKI JL, BURKE AC et al. (2001). Assembly of trunk and limb blood vessels involves extensive migration and vasculogenesis of somite-derived angioblasts. Dev Biol 234: 352-364.

BANGS F, WELTEN M, DAVEY MG et al. (2010). Identification of genes downstream of the Shh signalling in the developing chick wing and syn-expressed with Hoxd13 using microarray and 3D computational analysis. Mech Dev 127: 428-441.

BANGSF, ANDERSON KV (2017). Primary Cilia and Mammalian Hedgehog Signaling. Cold Spring Harb Perspect Biol pii: a028175. doi: 10.1101/cshperspect.a028175.

BEEDIE SL, MAHONY C, WALKER HM, et al. (2016a). Shared mechanism of teratogenicity of anti-angiogenic drugs identified in the chicken embryo model. Sci. Rep. 6: 30038.
BEEDIE SL, RORE HM, BARNETT S et al. (2016b). In vivo screening and discovery of novel candidate thalidomide analogues in the zebrafish embryo and chicken embryo model systems. Oncotarget 7: 33237-33245

BOARDMAN PE, SANZ-EZQUERRO J, OVERTON IM etal. (2002). Acomprehensive collection of chicken cDNAs. Curr Biol 12: 1965-1969.

BOYLEN JB, HORNE HH, JOHNSON WJ (1963). Teratogenic effects of thalidomide and related substances. Lancet 1: 552 .

CARRINGTON JL, FALLON JF (1984). Evidence that the ectoderm is the affected germ layer in the wingless mutant chick embryo. J Exp Zool 232: 297-308.

CHANG CF, SCHOCK EN, O'HARE EA et al. (2014) The cellular and molecular etiology of the cranial defects in the avian ciliopathic mutant talpid'. Development 141: 3003-3012.

CHINNAIYAK, TICKLEC, TOWERSM (2014) Sonic hedgehog-expressing cells in the developing limb measure time by an intrinsic cell cycle clock. Nat Commun 5: 4230 .

CHRIST B, JACOB HJ, JACOB M (1977). Experimental analysis of the origin of the wing musculature in avian embryos. Anat Embryol (Berl) 150: 171-186.

COHN M, IZPISÚA- BELMONTE JC, ABUD H et al. (1995). Fibroblast growth factors induce additional limb development from the flank of chick embryos. Cell 80: 239-246.

COOPER KL, HU JK, TEN BERGE D et al. (2011). Initiation of proximo distal patterning in the vertebrate limb by signals and growth. Science 332: 1083-1086.

DAHN RD, FALLON JF (2000). Interdigital regulation of digit identity and homeotic transformation by modulated BMP signaling. Science 289: 438-441.

D'AMATO RJ, LOUGHNAN MS, FLYNN E, et al. (1994). Thalidomide is an inhibitor of angiogenesis. Proc Natl Acad Sci USA 91: 4082-4085.

DAVEY MG, PATON IR, YIN Y et al. (2006). The chicken talpid ${ }^{3}$ gene encodes a nove protein essential for Hedgehog signaling. Genes Dev 20: 1365-1377.

DAVEY MG, JAMES J, PATON IR et al. (2007). Analysis of talpid ${ }^{3}$ and wild-type chicken embryos reveals roles for Hedgehog signalling in development of the limb bud vasculature. Dev Biol 301: 155-165.

D'SOUZA D, McDIARMID J, TICKLE C (1998). A polydactylous human foot with 'double-dorsal' toes. J Anat 193: 121-130.

DUDLEYAT, ROS MA, TABIN CJ (2002). A re-examination of proximodistal patterning during vertebrate limb development. Nature 418: 539-544.

DUNN IC, PATON IR, CLELLAND AK et al. (2011). The chicken Polydactyly (Po) locus causes allelic imbalance and ectopic expression of Shh during limb development. Dev Dyn 240: 1163-1172.

EDE DA, KELLY WA (1964). Developmental abnormalities in the trunk and limbs of the talpid ${ }^{3}$ mutant of the fowl. J Embryol Exp Morphol 12: 339-356.

EDE DA, SHAMSLAHIDJANI M (1983). Ectoderm/mesoderm recombination, dissociation and cell aggregation studies in normal and talpids mutant avian embryos. Prog Clin Biol Res 110 Pt A: 45-55.

EICHELE G, TICKLE C, ALBERTS BM (1984). Microcontrolled release of biologically active compounds in chick embryos: beads of 200-microns diameter for the local release of retinoids. Anal Biochem 142: 542-555.

FALLON JF and CROSBY GM (1977). Polarizing zone activity in limb buds of amniotes. In Limb and Somite Morphogenesis (Ed. D.A. Ede, J.R. Hinchliffe, M. Balls). Cambridge University Press, Cambridge, pp. 55-71.

FISHER M, DOWNIE H, WELTEN MC et al. (2011). Comparative analysis of 3D expression patterns of transcription factor genes and digit fate maps in the developing chick wing. PLoS One 6: e18661.

GREEN JB, SHARPE J (2015). Positional information and reaction-diffusion: two big ideas in developmental biology combine. Development 142: 1203-1211.

GROS J, TABIN CJ (2014). Vertebrate limb bud formation is initiated by localized epithelial-to-mesenchymal transition. Science 343: 1253-1256.

GALLOWAY JL, DELGADO I, ROS MA et al. (2009). A reevaluation of X-irradiationinduced phocomelia and proximodistal limb patterning. Nature 460: 400-404.

HILL RE, LETTICE LA (2013). Alterations to the remote control of Shh gene expression cause congenital abnormalities. Philos Trans R Soc Lond B 368: 20120357.

HINCHLIFFE JR, EDE DA (1973). Cell death and the development of limb form and skeletal pattern in normal and wingless (ws) chick embryos. J Embryol Exp Morphol 30: 753-772.

JOHNSON EJ, NEELY DM, DUNN IC et al. (2014). Direct functional consequences 
of ZRS enhancer mutation combine with secondary long range $\mathrm{SHH}$ signalling effects to cause preaxial polydactyly. Dev Biol 392: 209-220.

JURAND A (1966). Early changes in limb buds of chick embryos after thalidomide treatment. J Embryol Exp Morphol 16: 289-300.

KAWAKAMI Y, CAPDEVILA J, BUSCHER D et al. (2001). WNT signals control FGFdependent limb initiation and AER induction in the chick embryo. Cell104:891-900.

LAUFER E, NELSON CE, JOHNSON RL et al. (1994). Sonic hedgehog and Fgf-4 act through a signaling cascade and feedback loop to integrate growth and patterning of the developing limb bud. Cell 79: 993-1003.

LEWIS KE, DROSSOPOULOU G, PATON IR et al. (1999). Expression of ptc and gli genes in talpid ${ }^{3}$ suggests bifurcation in Shh pathway. Development 126:2397-2407.

LOGAN C, HORNBRUCH A, CAMPBELL I et al. (1997). The role of Engrailed in establishing the dorsoventral axis of the chick limb. Development 124:2317-2324.

MAAS SA, SUZUKI T, FALLON JF (2012). Identification of spontaneous mutations within the long-range limb-specific Sonic hedgehog enhancer (ZRS) that alter Sonic hedgehog expression in the chicken limb mutants oligozeugodactyly and silkie breed. Dev Dyn 240: 1212-1222.

MAHONY C, McMENEMY S, RAFIPAY AJ et al. (In Press). CPS49-induced neurotoxicity does not cause limb patterning anomalies in developing chicken embryos. $J$ Anat doi: dx.doi.org/10.1111/joa.12712

MAHONY C, VARGESSON N (2013). Molecular analysis of regulative events in the developing chick limb. J Anat 223: 1-13.

MCCREDIE J, MCBRIDE WG (1973). Some congenital abnormalities: possibly due to embryonic peripheral neuropathy. Clin Radiol 24: 204-211.

MERCADER N, LEONARDO E, PIEDRA ME, et al. (2000) Opposing RA and FGF signals control proximodistal vertebrate limb development through regulation of Meis genes. Development 127: 3961-3970

MICHAUD JL, LAPOINTE F, Le DOUARIN NM (1997). The dorsoventral polarity of the presumptive limb is determined by signals produced by the somites and by the lateral somatopleure. Development 124: 1453-1463.

MONTAVON T, DUBOULE D (2013). Chromatin organization and global regulation of Hox gene clusters. Philos Trans R Soc Lond B 368: 20120367.

MORGAN BA, IZPISÚA- BELMONTE JC, DUBOULE D et al. (1992). Targeted misexpression of Hox-4.6 in the avian limb bud causes apparent homeotic transformations. Nature 358: 236-239.

NELSON CE, MORGAN BA, BURKE AC et al. (1996). Analysis of Hox gene expression in the chick limb bud. Development 122: 1449-1466.

NISHIMOTO S, LOGAN MP (2016). Subdivision of the lateral plate mesoderm and specification of the forelimb and hindlimb forming domains. Semin Cell Dev Biol 49: 102-108.

NISWANDER L, TICKLE C, VOGEL A et al. (1993). FGF-4 replaces the apical ectodermal ridge and directs outgrowth and patterning of the limb. Cell 75: 579-587.

NISWANDER L, JEFFREY S, MARTIN GR et al. (1994). A positive feedback loop coordinates growth and patterning in the vertebrate limb. Nature 371: 609-612.

$\mathrm{OHUCHI} \mathrm{H,} \mathrm{SHIBUSAWAM,} \mathrm{NAKAGAWAT} \mathrm{et} \mathrm{al.} \mathrm{(1997a).} \mathrm{A} \mathrm{chick} \mathrm{wingless} \mathrm{mutation}$ causes abnormality in maintenance of Fgf8 expression in the wing apical ridge, resulting in loss of the dorsoventral boundary. Mech Dev 62: 3-13.

OHUCHI H, NAGAWA T, YAMAMOTO A et al. (1997b). The mesenchymal factor, FGF10, initiates and maintains the outgrowth of the chick limb bud through interaction with FGF8, an apical ectodermal factor. Development 124: 2235-2244.

PEARSE RV, SCHERZ PJ, CAMPBELL JK et al. (2007). A cellular lineage analysis of the chick limb bud. Dev Biol 310: 388-400.

PICKERING J, TOWERS M (2016). Inhibition of Shh signalling in the chick wing gives insights into digit patterning and evolution. Development 143: 3514-3521.

PIZETTE S, ABATE-SHEN C, NISWANDER L (2001). BMP controls proximodistal outgrowth, via induction of the apical ectodermal ridge, and dorsoventral patterning in the vertebrate limb. Development 128: 4463-4474.

RIDDLE RD, JOHNSON RL, LAUFER E et al. (1993) Sonic hedgehog mediates the polarizing activity of the ZPA. Cell 75: 1401-1416.

RIDDLE RD, ENSINI M, NELSON CE et al. (1995). Induction of the LIM homeobox gene $L m x 1$ by Wnt-7a establishes dorsoventral pattern in the vertebrate limb. Cell 83: 631-640.

ROBB EA, GITTER CL, CHENG HH et al. (2011). Chromosomal mapping and candidate gene discovery of chicken developmental mutants and genome-wide variation analysis of MHC congenics. $J$ Hered 102: 141-156.

ROMANOFF AL (1972). Pathogenesis of the avian embryo. An analysis of causes of malformations and prenatal death. Wiley, New York. 464 pp.

ROSMA, DAHNRD, FERNANDEZ-TERAN M etal. (2003). The chick oligozeugodactyly (ozd) mutant lacks sonic hedgehog function in the limb. Development 130:527-537.

ROSELLO-DIEZA, ROS MA, TORRES M (2011). Diffusible signals not autonomous mechanisms determine the main proximodistal limb subdivision. Science 332 1086-1088.

SABHERWAL N, BANGS F, ROTH R et al. (2007). Long-range conserved non-coding $\mathrm{SHOX}$ sequences regulate expression in developing chicken limband are associated with short stature phenotypes in human patients. Hum Mol Genet 16: 210-222.

SAIZ-LOPZ P, CHINNAIYA K, CAMPA VM et al. (2015). An intrinsic timer specifies distal structures of the vertebrate limb. Nat Commun. 6: 8108.

SAIZ-LOPZ P, CHINNAIYA K, TOWERS M et al. (2017). Intrinsic properties of limb bud cells can be differentially reset. Development 144: 479-486.

SANDERS TA, LLAGOSTERA E, BARNAM (2013). Specialized filopodia direct longrange transport of SHH during vertebrate tissue patterning. Nature 497: 628-632.

SANZ-EZQUERRO JJ, TICKLE C (2003). Fgf signaling controls the number of phalanges and tip formation in developing digits. Curr Biol 13: 1830-1836.

SIAMWALAJH, VEERIAH V, PRIYAMK, etal. (2012). Nitric oxide rescues thalidomide mediated teratogenicity. Sci Rep 2: 679.

SAUNDERS JW (1948). The proximo-distal sequence of origin of the parts of the chick wing and the role of the ectoderm. J Exp Zool 108: 363-403.

SAUNDERS JW, GASSELING MT (1968). Ectodermal-mesenchymal interactions in the origin of limb symmetry. In Mesenchymal-epithelial Interactions (Eds. R. Fleischmeyer and R. E. Billingham). Williams and Wilkins, Baltimore, pp. 78-97.

SAUNDERS JW (1977). The experimental analysis of chick limb development. In Limb and Somite Morphogenesis (Eds. D.A. Ede, J.R. Hinchliffe, M. Balls). Cambridge University Press, Cambridge, pp. 1-24.

SHELLSWELL GB and WOLPERT L (1977). The pattern of muscle and tendon development in the chick wing. In Limb and Somite Morphogenesis (Eds. D.A Ede, J.R. Hinchliffe, M. Balls). Cambridge University Press, Cambridge, pp. 71-86.

SMYTH JR, SREEKUMAR GP, COYLE CA et al. (2000). A new recessive ametapodia mutation in the chicken (Gallus domesticus). J Hered 91: 340-342.

STEPHEN LA, TAWAMIE H, DAVIS GM et al. (2015). TALPID3 controls centrosome and cell polarity and the human ortholog KIAA0586 is mutated in Joubert syndrome (JBTS23). Elife 4. pii: e08077.

STRECKER TR, STEPHENS TD (1983). Peripheral nerves do not play a trophic role in limb skeletal morphogenesis. Teratology 27: 159-167.

SUMMERBELL D, LEWIS JH, WOLPERT L (1973). Positional information in chick limb morphogenesis. Nature 244: 492-496.

SUMMERBELL D (1974). A quantitative analysis of the effect of excision of the AER from the chick limb-bud. J Embryol Exp Morphol 32: 651-660.

SUZUKI T, TAKEUCHI J, KOSHIBA-TAKEUCHI K et al. (2004). Tbx genes specify posterior digit identity through Shh and BMP signaling. Dev Cell 6: 43-53.

SUZUKIT, HASSO SM, FALLONJF (2008) Unique SMAD1/5/8 activity at the phalanxforming region determines digit identity. Proc Natl Acad Sci USA 105: 4185-4190.

TABIN CJ (1998). Adevelopmental model for thalidomide defects. Nature396:322-323.

THERAPONTOS C, ERSKINE L, GARDNER E, et al. (2009). Thalidomide induces limb defects by preventing angiogenic outgrowth during early limb formation. Proc Natl Acad Sci USA 106: 8573-8578.

TICKLE C, ALBERTS B, WOLPERT L et al. (1982). Local application of retinoic acid to the limb bud mimics the action of the polarizing region. Nature 296: 564-565.

TICKLE C, EICHELE G (1994). Vertebrate limb development. Ann Rev Cell Biol 10, 121-152.

TICKLE C (2015). How the embryo makes a limb: determination, polarity and identity J Anat 227: 418-430.

TICKLE C (2017). An historical perspective on the pioneering experiments of John Saunders.Dev Biol (dx.doi.org/10.1016/j.ydbio.2017.05.028)

TICKLE C, TOWERS M (2017). Sonic Hedgehog Signaling in Limb Development Front Cell Dev Biol 5: 14

TIECKE E, BANGS F, BLASCHKE R et al. (2006). Expression of the short stature homeobox gene Shox is restricted by proximal and distal signals in chick limb 
buds and affects the length of skeletal elements. Dev Biol 298: 585-596.

TOWERS M, MAHOOD R, YIN Y et al. (2008). Integration of growth and specification in chick wing digit-patterning. Nature 452: 882-886.

TOWERS M, TICKLE C (2009). Growing models of vertebrate limb development. Development 136: 179-190.

TOWERS M, SIGNOLET J, SHERMAN A et al. (2011). Insights into bird wing evolution and digit specification from polarizing region fate maps. Nat Commun 2: 426.

VARGESSON N (2013). Thalidomide Embryopathy: an enigmatic challenge. ISRN Dev. Biol. (http://dx.doi.org/10.1155/2013/241016).

VARGESSONN (2015). Thalidomide-induced teratogenesis: History and mechanisms. Birth Defects Research (Part C) 105: 140-156.

VARGESSON N, LAUFER E (2001). Smad7 misexpression during embryonic angiogenesis causes vascular dilation and malformations independently of vascular smooth muscle cell function. Dev Biol 240: 499-516.

VARGESSON N, LAUFER E (2009). Negative Smad expression and regulation in the developing chick limb. PLoS One 4: e5173.

VERON N, QU Z, KIPEN PA et al. (2015). CRISPR mediated somatic cell genome engineering in the chicken. Dev Biol 407: 68-74.

VOGEL A, RODRIGUEZ C, WARNKEN W et al. (1995). Dorsal cell fate specified by chick Lmx1 during vertebrate limb development. Nature 378: 716-720.

VOKES SA, JI H, WONG WH et al. (2008). A genome-scale analysis of the cisregulatory circuitry underlying Shh-mediated patterning of the mammalian limb. Genes Dev 22: 2651-2663.

WANG Z, YOUNG RL, XUE H et al. (2011). Transcriptomic analysis of avian digits reveals conserved and derived digit identities in birds. Nature 477: 583-586.

WELLIK DM, CAPECCHIMR (2003). Hox10 and Hox11 genes are required to globally pattern the mammalian skeleton. Science 301: 363-367.
WHITSEL AI, JOHNSON CB, FOREHAND CJ (2002). An in ovo chicken model to study the systemic and localized teratogenic effects of valproic acid. Teratology 66: 153-163.

WILBY O, EDE DA (1975). A model generating the pattern of cartilage skeletal elements in the embryonic chick limb. J Theor Biol 52: 199-217.

WOLPERT L (1969). Positional information and the spatial pattern of cellular differentiation. J Theor Biol 25: 1-47.

WOLPERT L (1989). Positional information revisited. Development 107: 3-12.

WOLPERT L (2018). From soil mechanics to chick development. Int J Dev Biol. 62 : (dx.doi.org. 10.1387/ijdb.180030-LW).

WOLPERT L, TICKLE C, SAMPFORD M (1979). The effect of cell killing by X-irradiation on pattern formation in the chick limb. J Embryol Exp Morph 50: 175-193.

WOOLLEY TE, BAKER RE, TICKLE C et al. (2014). Mathematical modelling of digit specification by a sonic hedgehog gradient. Dev Dyn 243: 290-298.

YANG Y, NISWANDER L (1995). Interaction between the signaling molecules WNT7a and $\mathrm{SHH}$ during vertebrate limb development: dorsal signals regulate anteroposterior patterning. Cell 80: 939-947.

YIN Y, BANGS F, PATON IR et al. (2009). The Talpid ${ }^{3}$ gene (KIAA0586) encodes a centrosomal protein that is essential for primary cilia formation. Development 136: $655-664$

ZENG X, GOETZ JA, SUBER et al. (2001). A freely diffusible form of Sonic hedgehog mediates long-range signalling. Nature 411: 716-720.

ZHANG Z, NIE C, JIAY et al. (2016). Parallel Evolution of Polydactyly Traits in Chinese and European Chickens. PLoS One. 11: e0149010.

ZUNIGAA, ZELLER R, PROBST S (2012). The molecular basis of human congenital limb malformations. Wiley Interdiscip Rev Dev Biol 1: 803-822.

ZWILLINGE (1974). Effects of contact between mutant wingless limb buds and those of genetically normal chick embryos: confirmation of a hypothesis. DevBio/39:37-48. 


\section{Further Related Reading, published previously in the Int. J. Dev. Biol.}

Comprehensive analysis of fibroblast growth factor receptor expression patterns during chick forelimb development Caroline J. Sheeba, Raquel P. Andrade, Delphine Duprez and Isabel Palmeirim

Int. J. Dev. Biol. (2010) 54: 1517-1526

https://doi.org/10.1387/ijdb.092887cs

The expression of teneurin- 4 in the avian embryo: potential roles in patterning of the limb and nervous system Daniela Kenzelmann Broz, Richard P. Tucker, Nathaniel T. Leachman and Ruth Chiquet-Ehrismann

Int. J. Dev. Biol. (2010) 54: 1509-1516

https://doi.org/10.1387/ijdb.103139dk

Vertebrate limb regeneration and the origin of limb stem cells

Susan V Bryant, Tetsuya Endo and David M Gardiner

Int. J. Dev. Biol. (2002) 46: 887-896

http://www.intjdevbiol.com/web/paper/12455626

Retinoic acid and limb regeneration--a personal view

Malcolm Maden

Int. J. Dev. Biol. (2002) 46: 883-886

http://www.intjdevbiol.com/web/paper/12455625

Programmed cell death in the developing limb

Vanessa Zuzarte-Luís and Juan M Hurlé

Int. J. Dev. Biol. (2002) 46: 871-876

http://www.intjdevbiol.com/web/paper/12455623

Positional information in vertebrate limb development; an interview with Lewis Wolpert Cheryll Tickle

Int. J. Dev. Biol. (2002) 46: 863-867

http://www.intjdevbiol.com/web/paper/12455621

The early history of the polarizing region: from classical embryology to molecular biology Cheryll Tickle

Int. J. Dev. Biol. (2002) 46: 847-852

http://www.intjdevbiol.com/web/paper/12455619

Developmental basis of limb evolution

$J$ Richard Hinchliffe

Int. J. Dev. Biol. (2002) 46: 835-845

http://www.intjdevbiol.com/web/paper/12455618

5 yr ISI Impact Factor $(2016)=2.421$
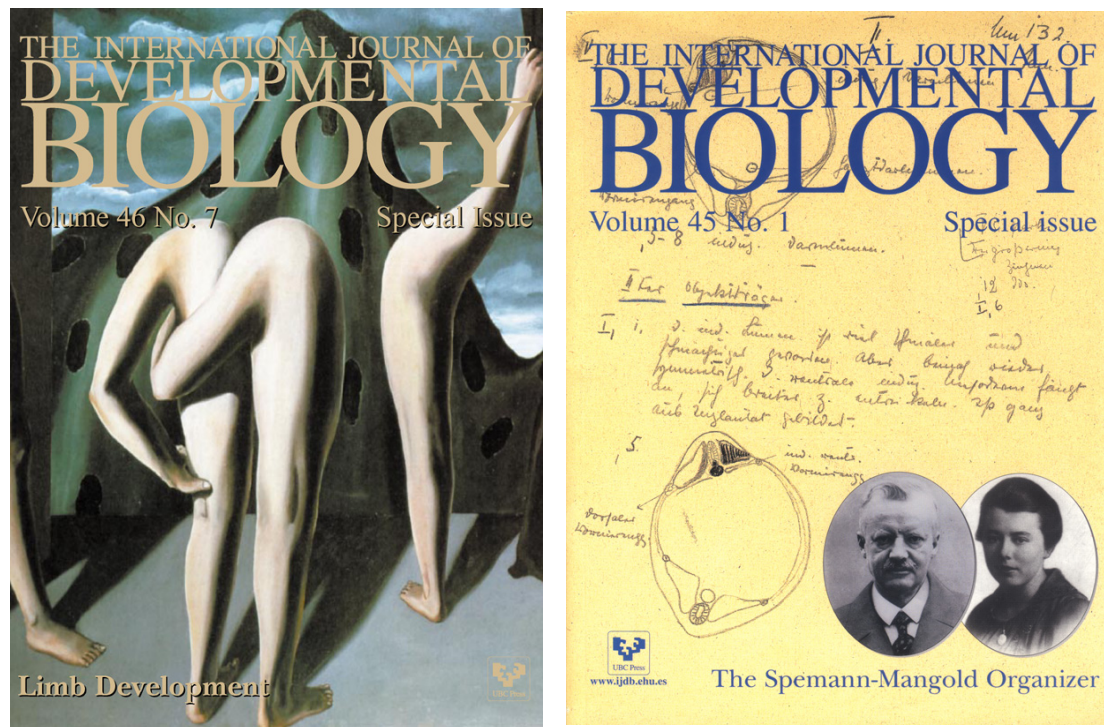

Volume 45 No. 1

Special issue
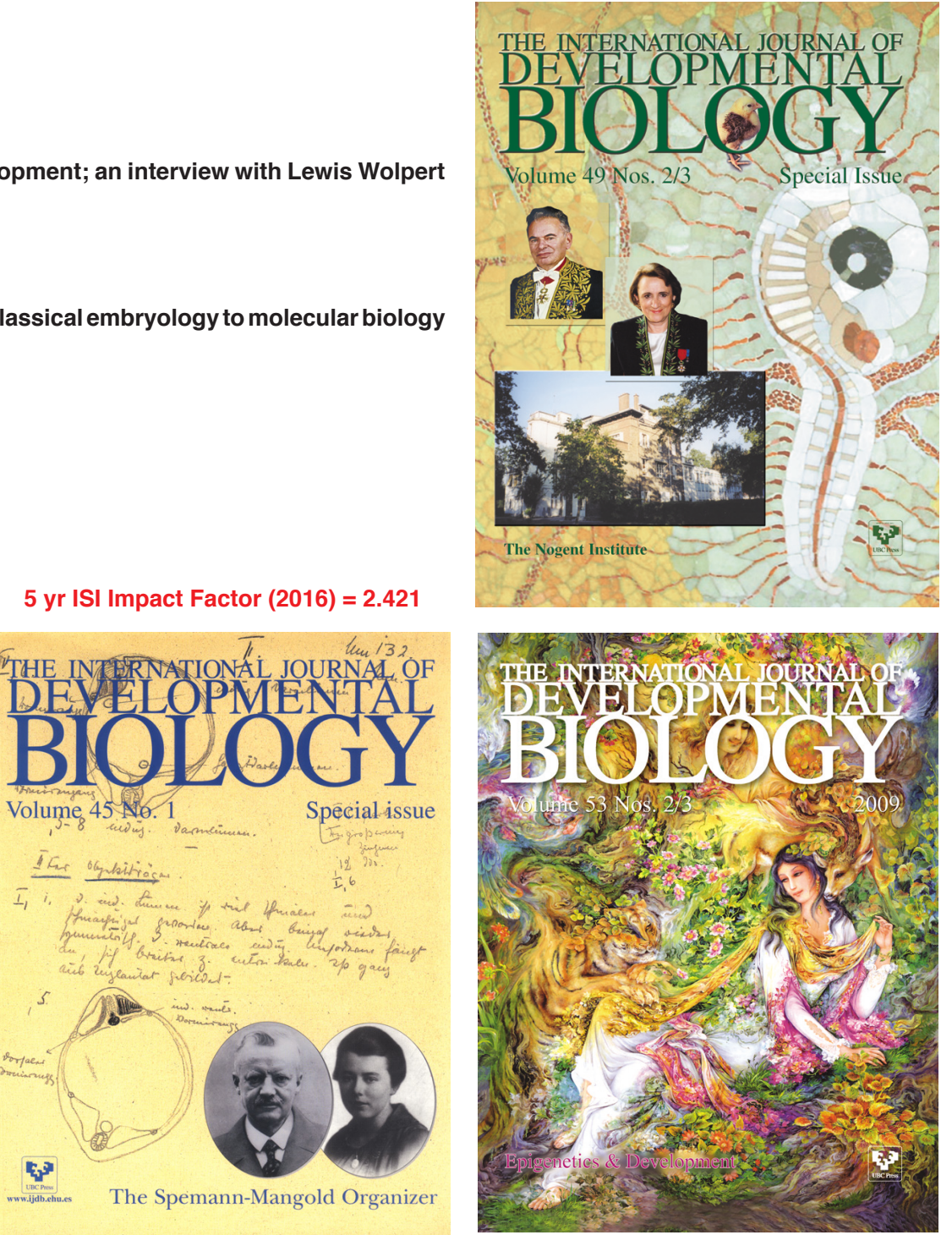